\title{
The Research on the Comparison of Hanfu Fashion Short Videos on Douyin and Tik Tok
}

\author{
Lian Tang ${ }^{1, a, *,}$, Chenyi Wang ${ }^{2, \mathrm{~b}, *, \dagger}$ \\ ${ }^{1}$ Queen Mary University of London Engineering School, Northwestern Polytechnical University, Shaanxi, 710072, \\ P.R. China \\ ${ }^{2}$ Shanghai International High School Of Britain, Australia \& New Zealand, Shanghai, 201101, P.R.China. \\ ${ }^{*}$ Corresponding author.Email: ${ }^{a}$ lian.tang@se18.qmul.ac.uk, ${ }^{b}$ Chenyiw18@gmail.com \\ These authors contributed equally.
}

\begin{abstract}
Hanfu, also called "Han clothing" in Chinese, is the traditional clothing for Han Chinese people. As short videos media, Douyin and Tik Tok provide platforms for Hanfu enthusiasts. Hanfu on these applications illustrates different communication of Hanfu culture as for different audiences in China and other foreign countries. To explore an appropriate way of intercultural communication on Hanfu, the research adopted qualitative research by sampling related videos and comments from Douyin and Tik Tok. The media presentation of Hanfu fashion determines audience recognition of it. Through analysing the hottest Hanfu videos on Douyin and Tik Tok, it is found that Hanfu culture communications are considered to be on different stages for Chinese and individuals in other countries.
\end{abstract}

Keywords: Hanfu clothing, Douyin, Tik Tok, Short videos

\section{INTRODUCTION}

Chinese civilization is named "Hua-Xia" in Chinese words, where "Hua" refers to the beauty of dress and "Xia" is derived from great etiquette [1]. As the largest ethnic group within China, Han Chinese people had worn their ethnic clothing for thousands of years. These clothes had witnessed the habits and aesthetics of Han people from different dynasties in China [2, 3]. Hanfu, which means "Han clothing", is the conventional clothing for Han Chinese people and is considered a significant part of Chinese culture [2, 4]. Because of historical reasons, Hanfu was replaced and disappeared in the 18th century. At the beginning of the 21st century, this Chinese costume was reintroduced into Chinese people's daily life [2, 3]. A worker called Wang Letian took to the streets in his homemade Hanfu in 2003, followed by an increasing number of young people who have taken part in the 'Hanfu revival movement' to rejuvenate the nation's culture [3]. Nowadays, Hanfu has become a significant fashion culture trend rather than normal ethnic clothes, for there are Internet culture, consumerism, cultural confidence, and other factors behind these clothes [3]. Statistics showed that China's Hanfu enthusiasts increased from 2 million in 2018 to 3.6 million in 2019 and is expected to reach 6.9 million in 2021 , with over 70 percent of them being Generation Z-ers aged between 16 and 24[5]. Recently, internet social media provide platforms for Hanfu lovers, and short video platforms bring new opportunities for the inheritance and development of Hanfu [3, 6].

Established in 2016, Douyin is a Chinese mobile social platform dedicated to publishing 15 -second music creative short videos [7]. Users can add music and effects to short-form videos through the app with various editing capabilities, then share them to the web [7]. Moreover, people could watch videos via a recommendation mechanism, which prioritizes the content of users nearby and measures whether the video has been recommended according to the user's viewing time, likes, comments, and other indicators [7]. According to the "Douyin Data Report 2020", daily active users of Douyin exceeded 600 million as of August 2020 [7]. Even though the new users had relatively declined, nearly forty thousand new users were still entering Tik Tok in 2020[8]. The user scale of Douyin still keeps the lead in the mobile short video industry in China [8]. Tik Tok, the overseas version of Douyin, enjoys similar functions and instructions for users as Douyin, for they are launched by the same company [9]. It has been active in over 150 million users (500 million monthly active users) around the 
world, covering a total of over 60 million subscribers [9, 10]. As of 2020, Tik Tok counted an estimated 65.9 million monthly active users in the United States, Indonesia, Russia, and Japan followed. [10, 11]. The largest difference between these applications is that the audiences of Douyin are Chinese while those of Tik Tok come from all around the world. Tik Tok is generally not used in China Mainland, so there are few crossovers of user groups.

With increasing attention on traditional culture in China, Hanfu has become a clothing trend and is derived into a large industry, which illustrates economic development and a cultural phenomenon [5]. Hanfu has become a heated topic, and most research on it focuses on cultural communication. Ji divided Hanfu into two types, "ancient Hanfu" and "contemporary Hanfu" [12]. Because of the historical diversity, "ancient Hanfu" includes different forms of clothes in several dynasties [12]. "Contemporary Hanfu" is defined as the clothes that Hanfu enthusiasts have worn since the revival of the Hanfu culture movement in 2003[12, 13]. Modern Hanfu clothing style is generally considered as modified Hanfu, which has the characteristics of "ancient Hanfu" and meets the aesthetic standards of contemporary society in terms of style, colour, structure, and materials [12]. The popularity of modern Hanfu reflects the integration and deviation of aesthetic and identity [3]. Moving with the times, Hanfu clothing is generally classified in the light of dynasties, such as Qin, Tang, Ming [2]. According to Zhu's classification, the popular ethnic clothing includes magnificent, ethereal, and hermit styles with different colors, patterns, materials, and tailoring methods[3]. Magnificent style Hanfu gives people a solemn and gorgeous impression, mainly in Ming stand collar shirt or Ming jacket with strong color contrast and traditional patterns such as dragon, phoenix, and clouds [3]. Ethereal Hanfu is the mainstream of contemporary Hanfu at present, which contains mainly chest-length clothes made in the Tang Dynasty and a large loose outer coat in the Song Dynasty. Most materials are light and thin fabrics, such as yarn and chiffon, which look elegant. The colors are mostly with low saturation and high brightness, such as pink, pink, and goose yellow [3]. The Han clothes of hermit style mostly refer to the Wei and Jin Dynasties with very low saturation in color. There are few patterns on them, including bamboo, ink, crane, and other classical images commonly seen in Chinese literati [3].

Douyin has become a common communicating platform for Hanfu. Up to 2019, the number of topic videos with the tag Hanfu in Douyin has reached 670 thousand, and the total views have exceeded 18 billion times [14]. 78\% of Hanfu video uploaders have a goods window demonstrating that most Hanfu videos are commercial [5]. It is particularly important to create more refined and attractive communication content to attract the audience's attention and interest in the 15- second video [11]. In Cao's research, Tik Tok videos related to Hanfu could be classified into three categories: beauty, technology, and guide[5]. Beauty videos of Hanfu from merchants or lovers focus on the communication of clothing appearance and enjoy more views, which indicates that particular Hanfu looks could leave good impressions for users in 15 seconds [15]. The most popular beauty video of Hanfu in Douyin is the slow-motion of individuals with the skirt floating [5]. Pursuing a stronger visual effect, people in these videos often wear Hanfu in gentle color with silk fabrics shining in the light [5]. Some wear guides from advanced hobbyists aimed to communicate Hanfu culture through introductions of history and different sorts [15]. Han clothing on Douyin is mainly contemporary Hanfu, which is liked by female audiences.

Although there is no literature about Hanfu fashion on Tik Tok, it was recorded that Hanfu clothing elements appeared on western women's dresses in American Vogue magazine, according to Yao [16]. Because Japanese Kimono clothing came from Han clothing of China's Tang Dynasty, this clothing element was considered [16]. Compared with Qipao, another Chinese dress well known by foreigners, Hanfu show less influence [16]. While Hanfu has become popular in China in recent years, overseas Chinese have spread Hanfu culture to foreigners by establishing associations and organizing a series of traditional Chinese cultural activities in Hanfu [17]. In addition, the popularity of ancient Chinese TV dramas has also expanded the influence of Hanfu, especially in Asia [18]. However, the spread of Hanfu is also controversial abroad. Some commentators regarded the Hanfu fashion trend initiated by people to promote a nationalistic political agenda [19].

Researchers have studied a large amount of literature but found no relevant literature to compare Hanfu fashion style on Douyin and Tik Tok. Most literature about Hanfu on Tik Tok focuses on the scheme and technology of videos instead of clothing. There is no literature about Hanfu or other Chinese costumes in Tik Tok. It is significant to compare Hanfu fashion style on Douyin and Tik Tok, for it could spread Hanfu culture to more countries. As for different audiences of Douyin and Tik Tok, there could be some differences in Hanfu fashion style between these two platforms. Through differences, thoughts on this ethnic clothing of Chinese and people from other countries and reasons behind could be considered to explore an appropriate way of intercultural communication on Hanfu. Therefore, this study aims to compare the communication for Hanfu fashion short videos on Douyin and Tik Tok. 


\section{METHODOLOGY}

This essay will take the qualitative research method and take the short videos of Hanfu culture as samples to study the dissemination of Hanfu culture on Douyin and Tik Tok. The short videos of Hanfu culture on Douyin and Tik Tok studied in this paper are related to Hanfu. It includes knowledge about Hanfu, history, and culture related to Hanfu and short videos of people performing in Hanfu. From July 11 to July 19, 2021, influential and representative videos with different clothing styles were selected as samples to study the content of Hanfu culture communication on Douyin or Tik Tok. Firstly, on Douyin, “汉服 (Hanfu in Chinese characters)” was

keyed in the search bar while "Hanfu" was searched on Tik Tok, followed by recording views of Hanfu topic. Ignoring similar and uncorrelated ones, ten videos of Hanfu clothing with the most likes were considered. Then, the short videos with the top likes were recorded with likes and comments. In the light of Zhu's classification, videos were classified, and Hanfu clothing was analysed from 3 main aspects: style, colour, pattern [3]. In addition, the video styles and individual characters of ten videos were analysed.

\section{RESULTS AND DISCUSSIONS}

With 55 billion views, “汉服(Hanfu)” is a heated topic on Douyin, and more than 20 related topics are enjoyed with over 100 million views. The hottest video with “汉服(Hanfu)” tag had 3,210,000 likes and no less than 87,000 comments with a ratio of about $36: 1$ likes to comment. The comment with the most likes said "Make Hanfu popular", and many of the comments were asking how to buy or asking for a link to buy. Hanfu also has become popular on Tik Tok that the hashtag 'Hanfu' has been viewed more than 380 million times and the hashtag 'Chinese street photography' has been viewed 1.2 billion times. These videos reflect the fusion of Chinese traditional culture and modern life. In the 10 top Hanfu videos, there are at least 388,000 likes and up to about 779,000 , but the number of comments per video is smaller, with the ratio of likes to comments being about 55 to 1 . In the comments section of each video, many foreign netizens have posted admiring comments. 'China's fashion level is on another level!', 'How topping! They all seem very confident.', 'I've found the best channel on the earth forget everything else!'.

Chinese people attach great importance to their own culture, and many young people will often learn about the history of different periods [5]. More and more people like Hanfu and are willing to share this culture, making Hanfu culture a trend again. Overseas, many people only know that China has a history of thousands of years, and they do not understand or even know the culture of Hanfu, so the effect of Hanfu communication overseas is poor. In cross-cultural communication, historical events rather than costumes are often popularized, so Hanfu is at a disadvantage in cultural communication. However, the spread of Hanfu culture overseas has always been limited to a small circle of fans, unable to involve ordinary audiences other than Hanfu fans. Hanfu culture is often spread through the communication between fans interested in Hanfu and other young netizens interested in Hanfu or traditional culture to attract them into fans and expand the insiders of Hanfu culture. However, this neglects the publicity and popularization of the general public. Therefore, some strategies are considered to improve cross-cultural communication of Hanfu culture. Hanfu brands could be built, transforming Hanfu culture into commodities to enhance the influence and value of modern Hanfu. At the same time, the development of Hanfu industry should not only focus on Hanfu lovers. The target consumers should first take the young Hanfu lovers as the core and then spread to the foreigners of the same age. The utilization of media platforms is crucial to promote Hanfu culture. Interesting videos of women or men wearing Hanfu could be made to popularize Hanfu culture, to enhance the public's impression of Hanfu, and promote people's interest.

On Douyin, the number of videos of women wearing Hanfu was much higher than the number of videos of men wearing Hanfu, about 13:3. On Tik Tok, however, the ratio of women to men in Hanfu videos is about $9: 17$. The reasons of this difference are discussed as follow. There were more women than men who commented on videos on Douyin and Tik Tok. Secondly, most videos with Hanfu on Douyin were considered commercial value, while videos with this clothing on Tik Tok were uploaded primarily for appreciation and communication of Chinese culture. Therefore, Chinese women buy Hanfu for themselves, while foreign women appreciate men wearing Hanfu under the influence of Chinese costume TV series. Different clothing styles of Hanfu were also demonstrated in the light of statistical data. Firstly, Hanfu in ethereal style and magnificent style received the most views on Douyin, while on Tik Tok videos with Hanfu in dark, magnificent and ethereal style had the most views. The hermit style only appeared on Douyin once and never on Tik Tok from these videos. Then, most videos on Douyin illustrated Hanfu with lighter colors rather than that with darker colors on Tik Tok. The most widely used color of Hanfu on Douyin is red, and that on Tik Tok is black. Flowers, plants, trees, animal stripes were the patterns on these Hanfu clothing on both Douyin and Tik Tok, and there were more dragon patterns on Hanfu of Tik Tok.

It is supposed that Hanfu in the ethereal style with low saturation and high brightness colors was given the 
most attention in China. Although Hanfu movement makes Hanfu become a significant fashion trend, most Chinese people still have little knowledge of Hanfu and mistake TV drama clothing for Hanfu clothing. The clothing of Chinese Xianxia TV dramas, many of which showed fictional immortals' lives in ethereal Hanfu, left a deep impression on Chinese audiences [20]. When individuals watch these videos where beautiful people wear ethereal Hanfu, the thought of becoming immortals could obtain acceptance. Red is also the common color of Hanfu for women in these TV dramas showing vitality and charms. Then, Hanfu in magnificent style generally includes Han clothing in Ming Dynasty, which was the clothing style with the second most views. Ming Dynasty is the last dynasty of ancient China where Han people wore their Hanfu clothing. Because of close to Modern China, Ming Hanfu was recorded more information than other Hanfu and integrated with advantages of Hanfu from other dynasties, which contributed to more interests of audiences. Compared with Hanfu on Douyin, many Han clothing on Tik Tok was in the dark style. The most likely explanation of this interest was that black Hanfu clothing left a cool and magical impression on audiences from other countries. Black is a common color of clothing for individuals indicating their rigorousness or coolness. In addition, there was a kind of stereotype of some foreigners to Chinese magic from black Hanfu clothing. The common use of dragon patterns reflected the first impression for foreigners to China [16]. Although some foreigners had knowledge of Chinese culture from Chinese costume TV dramas with Hanfu wearers like Chinese, cultural diversities hardly ever enable them to comprehend well. The views of magnificent Hanfu videos were the second most on Tik Tok, and overseas Chinese focused on this Hanfu style. The thoughts of seeking roots led some overseas Chinese to learn intently and comprehend Chinese culture deeply. The magnificent Ming Hanfu has more cultural characteristics. They have a greater sense of identity when watching videos with people in this type of Hanfu. Overseas Chinese took an important part in Hanfu culture communication on social media, but this group was a small minority on Tik Tok from the comments of these Hanfu videos on this platform.

Among the Hanfu videos with the top ten views on Douyin and Tik Tok, most were collection videos of street shows. The performers on Douyin, who were often women, generally walked, circled, and ran with their Hanfu skirt fluttering. Attached with Chinese style song and rhythmic editing, these videos illustrated the performers were confident and elegant. There were also some people in Hanfu showing their particular talents. One of Hanfu videos on Douyin demonstrated a girl in Hanfu doing a led hold with a foot moving close to the head, which reflected that the girl is not simply beautiful but cool and brave rather than the conventional image of delicate and gentle. On Tik Tok, street shows focused on the men walking and smiling in Hanfu who looked composed, urbane, and affable or rigorous and cool. These characters of men were similar to those were shown in Chinese historical TV dramas appealing to an international audience. Some of the videos were combined with storylines of other foreign subcultures, such as skateboard and LGBT culture. Moreover, some Hanfu wear guide videos on Douyin indicated how to wear or collocate this clothing correctly. On Tik Tok, Hanfu cloths change videos were popular, as well. In general, audiences on Douyin preferred Hanfu videos showing feminine beauty ideal and cultural communication while those on Tik Tok had more interest in those videos illustrating Chinese historical drama style and intercourse with common foreign cultures.

The differences in Hanfu video on these two apps has both positive and negative effects. Media representation determines the audience's understanding of Hanfu. The positive impact is that different audiences have different preferences for clothing, and videos could show a variety of Hanfu fashion. Contemporary Hanfu originated from ancient Hanfu, and it could be more variable and creative to close to modern life [3]. Videos on Douyin focus on audiences' likes from foreign countries, so it is important to demonstrate Hanfu videos close to foreigners' preferences. The negative impact is that people who do not understand Chinese culture may consider the beauty of Hanfu on appearance instead of the culture behind it. Fashion trends are closely related to the connotation behind clothing. Therefore, to achieve good cross-cultural communication of Hanfu, the suggestions for the exhibition of Hanfu in short videos are as follows: First, combining Hanfu clothing with its culture in videos on Douyin. Some traditional cultural activities, such as writing or archery, could be shown in videos with individuals wearing Hanfu, which increases the influence of Hanfu culture in China. Then, Hanfu on Tik Tok could be presented with some foreign popular culture to show culture inclusiveness. For example, the clothing could be designed with lace elements, or people wearing Hanfu take skateboarding and sing Hip-hop songs in videos. In addition, Hanfu video producers could follow the trend of short video editing with music to illustrate a great variety of Hanfu applicable to various scenarios.

\section{CONCLUSION}

Comparing Hanfu fashion short videos on Douyin and Tik Tok shows different communication in China and other foreign countries. Hanfu attracted not only Chinese people but also many foreign consumers. It enjoyed more views on Douyin than Tik Tok due to insufficient cross-communication of Hanfu clothing. 
Hanfu is more favored by women than men in both China and other countries. Through Hanfu videos, Chinese women buy Hanfu for themselves, while foreign women appreciate men wearing Hanfu under the influence of Chinese costume TV series. Because of different audiences on Douyin and Tik Tok, Hanfu culture communications are considered different stages for Chinese and individuals in other countries. The advanced experience could be applied according to local conditions on Douyin and Tik Tok. Some Hanfu videos on Tik Tok concentrated on clothing appearance instead of the essence of Chinese traditional culture. The crosscultural communication of Hanfu is facing opportunities and challenges. The research on the cross-cultural communication of Hanfu began with general public consciousness of continuing the national cultural spirit and determination to protect the cultural diversity of the world. Target consumers should be considered Young Hanfu lovers firstly, the foreigners interested in Chinese culture followed by. The utilization of media platforms is crucial, so interesting videos of women or men wearing Hanfu from multiple cultural perspectives could be made to promote people's interest in Hanfu clothing and communicate Hanfu culture.

\section{REFERENCES}

[1] DU Yong-hao, Huaxia-Han nationality, Chinese nation and Chinese people[J]. Heilongjiang National Series 1, 2010.

[2] J. Xu. Exploring Hanfu, Master's thesis, Aalto University, 2019. http://urn.fi/URN:NBN:fi:aalto201911035983

[3] M. Zhu, B. Guo. Mutual infiltration and reversal of aesthetics and identity -- a discussion on the deep mechanism of contemporary Hanfu fashion. literature and Art Forum. 01 (2021): 118-122. Doi: 10.14039/j.cnki.cn43-1515/i.2021.01.022

[4] Q. Jiang, Hanfu, the traditional costume loved by the young, CGTN. Available at: https://news.cgtn.com/news/2019-08-05/Hanfuthe-traditional-costume-chased-by-the-youngISWzMbnvW0/index.html [Accessed 14 July,2021]

[5] People's Daily, Young culture fans dress to impress, Available

at: http://en.people.cn/n3/2020/0811/c90000-97202505.html [Accessed 14 July,2021]

[6] Q. Yan, Research on the Han costume culture in the shaking platform. Tik Tok $\{3\} .09$ (2020): 39-40. doi:CNKI:SUN:XBGS.0.2020-09-018.

[7] B. Zhang, C. Liu, Tik Tok short video APP traditional culture communication strategy, Audio- visual Circles.05 (2019): 51-55. doi:10.13994/j.cnki.stj.2019.05.014.

[8] C. Xiao, Research on the communication phenomenon of "Hanfu culture" in the new media environment, MA thesis, Jilin University, 2020.

[9] J. Herrman. How Tik Tok is rewriting the world, The New York Times[online],10 (2019). Available at:

https://www.nytimes.com/2019/03/10/style/whatis-tik-tok.html [Accessed 14 July,2021]

[10] K.E. Anderson, Getting acquainted with social networks and apps: it is time to talk about Tik Tok, Library Hi Tech News, 2020, Vol. 37 No. 4, pp. 712. https://doi.org/10.1108/LHTN-01-2020-0001

[11] B. Omar, W. Dequan, Watch, share or create: The influence of personality traits and user motivation on TikTok mobile video usage, International Association of Online Engineering, 2020.

[12] T. Zhang, Putting China's Traditional Hanfu on the World Stage, Women's Wear Daily[online], 2020, Available at: https://wwd.com/fashionnews/fashion-features/china-traditional-hanfustyle-fashion-1234638369/ [Accessed 15 July,2021]

[13] X. Wang, C. François, L. Renaud, From Niche Interest to Fashion Trend: Hanfu Clothing as a Rising Industry in China, International Journal of Arts Management, 2020, 23.1 (2020): 79-89

[14] People's Daily, Traditional hanfu costumes gain traction among China's younger generation, July 09, 2021, Available at: http://en.people.cn/n3/2021/0709/c900009870126.html [Accessed 16 July,2021]

[15] Cao Xin Yue. "Analysis of the propagation characteristics of Tik Tok on the shaking platform." news research guide 11.19 (2020): $67-$ 68. doi:CNKI:SUN:XWDK.0.2020-19-034.

[16] Y. Zeng, Chinese influence on western women's dress in American Vogue magazine, 1960-2009, LSU Doctoral Dissertations, 2011.

[17] Vogue Business Team, Decoding China’s Hanfu revival, 2020, Available at: https://www.voguebusiness.com/fashion/hanfuchina-revival-traditional-clothing [Accessed 17 July,2021]

[18] Global Times, Chinese TV series increasingly popular in overseas markets, 2018. Available at: https://www.globaltimes.cn/content/1133824.shtml [Accessed 17 July,2021] 
[19] J. Yeung, L. Lee, Wearing pride: Centuries-old Chinese fashion is making a comeback, CNN style[online], 2019. Available at: https://edition.cnn.com/style/article/hanfu-rise-intlhnk/index.html [Accessed 17 July,2021]

[20] Y. Jing, Reconstructing Ancient Chinese Cultural Memory in the Context of Xianxia TV Drama, Master Thesis, Uppsala University, 2021. 